\title{
Part A: Assessing the performance of the COMFA outdoor thermal comfort model on subjects performing physical activity
}

\author{
Natasha A. Kenny • Jon S. Warland • \\ Robert D. Brown • Terry G. Gillespie
}

Received: 9 November 2008 /Revised: 24 March 2009 / Accepted: 25 March 2009/Published online: 25 April 2009

(C) ISB 2009

\begin{abstract}
This study assessed the performance of the COMFA outdoor thermal comfort model on subjects performing moderate to vigorous physical activity. Field tests were conducted on 27 subjects performing $30 \mathrm{~min}$ of steady-state activity (walking, running, and cycling) in an outdoor environment. The predicted COMFA budgets were compared to the actual thermal sensation (ATS) votes provided by participants during each 5 -min interval. The results revealed a normal distribution in the subjects' ATS votes, with $82 \%$ of votes received in categories 0 (neutral) to +2 (warm). The ATS votes were significantly dependent upon sex, air temperature, short and long-wave radiation, wind speed, and metabolic activity rate. There was a significant positive correlation between the ATS and predicted budgets (Spearman's rho $=0.574, P<0.01$ ). However, the predicted budgets did not display a normal distribution, and the model produced erroneous estimates of the heat and moisture exchange between the human body and the ambient environment in $6 \%$ of the cases.
\end{abstract}

Keywords Thermal comfort - Outdoor environment . Human $\cdot$ Physical activity $\cdot$ COMFA Model

\footnotetext{
N. A. Kenny $(\triangle)$

Teaching Support Services, University of Guelph,

Guelph, ON, Canada

e-mail: nkenny@uoguelph.ca

J. S. Warland • T. G. Gillespie

Department of Land Resource Science, University of Guelph, Guelph, ON, Canada

R. D. Brown

School of Environmental Design and Rural Development, University of Guelph,

Guelph, ON, Canada
}

\section{Introduction}

Thermal comfort models are commonly applied as analytical tools to assess human responses to thermal environments. Outdoor thermal comfort models are designed to evaluate the body's energy balance based upon the heat and moisture flux between a person and the surrounding environment. Thermal neutrality or comfort is predicted when the heat gained through metabolic heat production and the absorbtion of short- and long-wave radiation is equal (or nearly equal) to the heat lost through convection, evaporation, and long-wave radiation emission. The body's physiological heat balance is then related to perceptions of thermal sensation (i.e., how warm/cool the body 'feels').

With increasing concerns related to human health and inactivity, sprawling urbanization, and the resounding threat and reality of climate change, there has been a increased interest in outdoor thermal comfort research (e.g., Gaitani et al. 2007; Harlan et al. 2006; Nikolopoulou and Lykoudis 2006; Nikolopoulou and Steemers 2003). The increasing commercial value of outdoor spaces for recreational activity and service sector interests such as restaurants, cafes, theme parks, and cultural events has also warranted increased interest in research pertaining to outdoor thermal comfort (Spagnolo and de Dear 2003a). Research has suggested that microclimatic parameters and individual perceptions of thermal environments are highly associated with the usability of outdoor spaces, and that the number of users and the duration of use of a space are likely to increase if it is thermally comfortable (Nikolopoulou et al. 2001; Thorsson et al. 2004, 2007; Johansson and Emmanuel 2006; Eliasson et al. 2007). The concept of 'bioclimatic urban design' has recently evolved to describe a climatesensitive approach to the planning and design of outdoor spaces (Eliasson et al. 2007), and outdoor thermal comfort 
models are certain to provide a critical tool for evaluating the suitability of spaces for various forms of outdoor activity.

In order to validate the performance of outdoor thermal comfort models, field research is required to relate the model outputs to subjective evaluations provided by participants. Research has suggested that thermal comfort models such as the predicted mean vote (Fanger 1972) and the physiologically equivalent temperature (PET) (Mayer and Hoppe 1987; Hoppe 1999) do not always provide an accurate assessment of subjective responses in outdoor thermal environments (Knez and Thorsson 2006; Nikolopoulou and Lykoudis 2006; Nikolopoulou and Steemers 2003; Spagnolo and de Dear 2003a; Nikolopoulou et al. 2001; Thorsson et al. 2004, 2007). In one of the most widely cited studies, Nikolopoulou and Steemers (2003) stated that there are great discrepancies between subjective and objective evaluations of thermal comfort, and that microclimatic parameters only accounted for $50 \%$ of the variation between actual and predicted thermal sensation votes.

Although thermal comfort models provide valuable tools for evaluating outdoor thermal environments, the physiological approach adopted by many energy balance-based models is limited because it does not consider psychological factors such as expectancy, perceived control, thermal history, time of exposure, environmental stimulation, and cultural influences on subjective evaluations of thermal environments (Knez and Thorsson 2006; Nikolopoulou and Steemers 2003; Thorsson et al. 2004). In general, subjects appear to have a much wider range of acceptability and accommodation in outdoor thermal environments, as compared to indoors (Johansson and Emmanuel 2006; Nikolopoulou et al. 2001). In comparison to indoor environments, there is a high degree of complexity and temporal and spatial variability in outdoor spaces. Not only is there a much wider range of conditions experienced by subjects in outdoor environments, but their psychological perception of an outdoor environment can greatly affect their range of thermal 'acceptability' (Nikolopoulou et al. 2001; Nikolopoulou and Steemers 2003; Spagnolo and de Dear 2003a; Nikolopoulou and Lykoudis 2006; Thorsson et al. 2004, 2007). That is because people expect an outdoor environment to be variable over space and time, and they have a perceived lack of control over outdoor conditions, so there is a subsequent widening of their perceived comfort zone (Spagnolo and de Dear 2003a). In addition, people can often quite easily adapt to changes in their outdoor thermal environment by choosing a more supportive location (e.g., move in and out of the shade/wind), or altering their behavior by adding or removing clothing or by drinking hot or cool fluids (Thorsson et al. 2004).

Most outdoor thermal comfort research has been structured to assess sedentary subjects, or those performing at relatively low ranges of metabolic output (sitting, standing, or walking slowly) (Nikolopoulou et al. 2001; Spagnolo and de Dear 2003a; Thorsson et al. 2004, 2007; Nikolopoulou and Lykoudis 2006). Few studies have focussed specifically on users performing physical activity, and of those that have, most have been theoretically based and have not involved validation and field testing on subjects performing at higher metabolic rates (Schiller 2001; Spagnolo and de Dear 2003b). Both the physiological and psychological responses of subjects may be further confounded by higher levels of outdoor activity (Maw et al. 1993). Given the fact that people are usually engaged in some sort of physical activity when outdoors, and exercise can greatly impact thermal comfort, it is important to address this research gap.

The purpose of this project was to assess the performance of the COMFA outdoor thermal comfort model (Brown and Gillespie 1986, 1995) on subjects performing moderate to vigorous physical activity.

It will be presented as a two-part paper. Part A, as follows, will assess the COMFA outdoor thermal comfort model on subjects performing moderate to vigorous physical activity (i.e., brisk walking, running, and cycling). Part B, which appears as a separate article in this issue, will suggest improvements to the COMFA model for application on subjects performing physical activity, based on empirical research related to the effect of wind and activity on the clothing microclimate.

\section{Materials and methods}

The following section will outline the methods applied to test the COMFA model against the subjective responses provided by subjects performing physical activity in an outdoor environment.

\section{Subjects and test locations}

A total of 27 physically active subjects ( 16 female and 11 male) participated in the study. The average age, weight, and height of the female participants was 27 years, $168 \mathrm{~cm}$, and $61 \mathrm{~kg}$, respectively, while the average for the males was 30 years, $181 \mathrm{~cm}$, and $78 \mathrm{~kg}$, respectively (Table 1). All volunteer subjects completed an informed consent and Physical Activity Readiness Questionnaire (PAR-Q) form as per the American College of Sports Medicine guidelines (ACSM 2006). The research protocol regarding the participation of human subjects was approved by the University of Guelph Research Ethics Board.

Two field tests were conducted on subjects walking briskly. The subjects were instructed to walk at a steady moderate pace for $30 \mathrm{~min}$. Participants were not permitted 
Table 1 Descriptive characteristics of the subjects who participated in the field studies $(n=27)$

\begin{tabular}{llll}
\hline \multicolumn{1}{l}{ Variable } & Mean & SD & Minimum-maximum \\
\hline Female $(n=16)$ & & & \\
Age (years) & 27.2 & 5.8 & $21-44$ \\
Height $(\mathrm{cm})$ & 168.1 & 6.3 & $155-180$ \\
Weight $(\mathrm{kg})$ & 60.8 & 4.8 & $54.4-70.3$ \\
Male $(n=11)$ & & & \\
Age (years) & 30.2 & 6.5 & $22-40$ \\
Height $(\mathrm{cm})$ & 181.4 & 7.1 & $170-196$ \\
Weight $(\mathrm{kg})$ & 77.9 & 10.1 & $53.1-90.7$ \\
\hline
\end{tabular}

to drink fluids during their exercise session. A total of 20 subjects (12 female and 8 male) participated in the first walking test, which took place along a sidewalk $120 \mathrm{~m}$ in length, at the University of Guelph, Guelph, Ontario, Canada $\left(43^{\circ} 33^{\prime} \mathrm{N}, 80^{\circ} 17^{\prime} \mathrm{W}\right.$, elevation $334 \mathrm{~m}$ above sea level) between 1350 and 1420 hours on 30 October 2006. The walking test was repeated on 15 ( 7 female and 8 male) of the subjects along a gravel road $200 \mathrm{~m}$ in length at the Elora Research Station $\left(43^{\circ} 38^{\prime} \mathrm{N}, 80^{\circ} 25^{\prime} \mathrm{W}\right.$, elevation $346 \mathrm{~m}$ above sea level) between 1350 and 1420 hours on 4 October 2007.

Five (3 male and 2 female) cyclists and six runners (4 female and 2 male) were tested twice during a total of 10 separate field tests from July to October, 2007. All but two of the test runners and cyclists were trained, competitive athletes. The test subjects were instructed to cycle or run at a steady moderate pace for $30 \mathrm{~min}$ along a gravel road $440 \mathrm{~m}$ in length at the Elora Research Station. Participants were not permitted to drink fluids during their exercise session.

At each study site, the route was level and unobstructed, and contained no canopy coverage. Due to the length of the designated routes, the subjects were required to "loop" back and forth. In order to avoid complications associated with precipitation, tests were conducted on fair weather days.

The test subjects wore comfortable clothing, which permitted freedom of movement and was deemed appropriate to the environmental conditions. Clothing insulation $\left(\mathrm{s} \mathrm{m}^{-1}\right)$ and permeability $\left(\mathrm{L} \mathrm{m}^{-2} \mathrm{~s}^{-1}\right)$ values were assigned in accordance with ISO (2007) and Havenith et al. (1990). The speed of the walkers, cyclists, and runners was recorded every 5-10 min during the field tests. The pace of the walkers was monitored using a wireless accelerometer (T6 Foot POD; Suunto,USA), which was worn by one of the subjects during the brisk walking tests. Metabolic Activity $\left(\mathrm{W} \mathrm{m}^{-2}\right)$ rates were determined using the activity codes and MET intensities listed in Ainsworth et al. (2000), where $1 \mathrm{MET}$ is equivalent to $58.15 \mathrm{~W} \mathrm{~m}^{-2}$ (Parsons 2003; Havenith et al. 2002).
Participant data

Subjects were asked to evaluate their thermal sensation along a 7-point scale (Fanger 1972) and rate of perceived exertion (RPE) along a 15-point scale (Borg 1982) every 5 min during their exercise session. At the same time, they were asked to evaluate how they would prefer to feel at that particular moment (Table 2). The subjects provided their radial neck pulse count over a 10 -s period every $10 \mathrm{~min}$. Subjects were instructed to aim for an intensity equivalent to an RPE of 12-13 ("somewhat hard") or a heart rate of approximately $60-69 \%$ of their heart rate maximum $\left(\mathrm{HR}_{\max }\right)$. This level of activity was chosen because physical activity guidelines recommend that adults accumulate $30 \mathrm{~min}$ or more moderate intensity exercise 4-7 times per week for optimal cardiovascular fitness (ACSM 1998).

Microclimate data

\section{6 field test}

For the October 2006 field tests, wind velocity was measured using a miniature impulse cup anemometer $(\mathrm{R} /$ MAI; Rauchfuss Instruments, Australia) and air temperature was measured using a thermocouple placed in a radiation shield which was ventilated using a $12-\mathrm{V}$ fan. Relative humidity data were collected and recorded every 10 minutes using an Assman Psychrometer (Model H331; Sacromento, CA).

Radiation was measured using a cylindrical radiation thermometer (CRT) (Kenny et al. 2008) and a CNR1 net radiometer (Model CNR1; Kipp \& Konen, Delft, Netherlands). The CNR1 net radiometer provided separate measurements for all four radiation flux components $\left(K_{T}\right.$, $K_{r}, L_{a}$, and $L_{g}$ ) and was secured on a mobile stand (PCS-1; Parktool, USA). To represent the radiative properties of a human the CRT was painted to have an albedo of 0.37 and an emissivity of 0.95 . The CRT was mounted vertically on a laminated plexiglass strip $(500 \times 60 \mathrm{~mm})$. The anemometer, CRT, and shielded thermocouple junction were placed on a sturdy tripod. All instruments were set at $1.3-1.4 \mathrm{~m}$ above the ground. Data were collected at 60 -s intervals

Table 2 Scale for subjective responses of preferred change in thermal sensation used by subjects during the field tests

\begin{tabular}{ll}
\hline Score & Preferred change \\
\hline+3 & Much warmer \\
+2 & Warmer \\
+1 & Slightly warmer \\
0 & No change \\
-1 & Slightly cooler \\
-2 & Cooler \\
-3 & Much cooler \\
\hline
\end{tabular}


using a datalogger (model 21X; Campbell Scientific Instruments, Logan, UT) and calculated as 5-min averages over the sampling period.

\section{7 field tests}

For the 2007 field tests, wind velocity was measured using a cup anemometer (Metone 014A; Metone, USA) and air temperature was measured using a thermocouple which was placed in a naturally ventilated radiation shield (Young, USA). Relative humidity data were collected and recorded every 5 min using an Assman Psychrometer (Model H331). All four radiation flux components $\left(K_{T}, K_{r}, L_{a}\right.$, and $\left.L_{g}\right)$ were measured separately using a CNR1 net radiometer (Model CNR1; Kipp \& Konen).

The CRT was modified from the 2006 study to minimize the effects of terrestrial radiation and conduction from the mount to the sensor by inserting it $2 \mathrm{~mm}$ into a piece of wood dowel, $60 \mathrm{~mm}$ in length and $25 \mathrm{~mm}$ in diameter. A metal rod, $9 \mathrm{~mm}$ in diameter, was then inserted $2 \mathrm{~mm}$ into the opposite end of the dowel for mounting in a clamp, and the CRT was secured at $90^{\circ}$ to the ground surface. It was ensured that no shadows were cast on the CRT during the 2006 and 2007 field tests.

All instruments were secured at $1.5-1.7 \mathrm{~m}$ above the ground. Data were collected at 10-s intervals using a datalogger (model 21X; Campbell Scientific Instruments) and calculated as averages over 5-min sampling periods.

Modeling Thermal Comfort using the Comfort Formula (COMFA) model

The energy budget for each participant was calculated every 5 min during the exercise session based on the COMFA outdoor thermal comfort model (Brown and Gillespie 1986, 1995). The COMFA model requires the following inputs: air temperature $\left({ }^{\circ} \mathrm{C}\right)$, relative humidity $(\%)$, wind speed $\left(\mathrm{m} \mathrm{s}^{-1}\right)$, clothing insulation $\left(\mathrm{s} \mathrm{m}^{-1}\right)$, clothing permeability $\left(\mathrm{L} \mathrm{m}^{2} \mathrm{~s}^{-1}\right)$, metabolic activity $\left(\mathrm{W} \mathrm{m}^{-2}\right.$ ), and long-wave and short-wave radiation absorbed $\left(\mathrm{W} \mathrm{m}^{-2}\right)$. For clarity, the equations applied in this study are presented in the following section.

\section{Metabolic heat production}

The metabolic heat generated by a person $\left(\mathrm{W} \mathrm{m}^{-2}\right)$ was estimated as:

$M=(1-f) M_{a}$

where $M_{a}$ is the metabolic intensity of the individual $\left(\mathrm{W} \mathrm{m}{ }^{-2}\right.$ ) and $f$ is a correction for the heat loss consumed through breathing, which is calculated as:

$f=0.150-(0.0173 e)-\left(0.0014 T_{a}\right)$ where $T_{a}$ is the ambient air temperature $\left({ }^{\circ} \mathrm{C}\right)$ and $\mathrm{e}$ is the ambient vapor pressure $(\mathrm{kPa})$.

\section{Convection}

Convective heat losses were calculated based upon Ohm's law analogy where the flux rate $\left(\mathrm{W} \mathrm{m}^{-2}\right)$ is equal to the concentration difference [temperature difference $\left({ }^{\circ} \mathrm{C}\right)$ between the 'surfaces'] divided by the resistances to the flow of energy from one surface to the other $\left(\mathrm{s} \mathrm{m}^{-1}\right)$. In the present study, the convective heat flux from a person has been modified from the original model (Brown and Gillespie 1986) to reflect the flow of heat from the skin surface of an individual, through to the ambient environment, rather than from the core of an individual to the ambient environment. The COMFA model does not incorporate a clothing area factor $\left(f_{c l}\right)$. The convective heat flux from a person $\left(\mathrm{W} \mathrm{m}^{-2}\right)$ was described by the equation:

$C O N V=\rho C_{p}\left(\frac{T_{s k}-T_{a}}{r_{c}+r_{a}}\right)$

where $\rho C_{p}$ is the volumetric heat capacity of air $(\sim 1212 \mathrm{~J}$ $\left.\mathrm{m}^{-3} \mathrm{~K}^{-1}\right), T_{s k}$ is the skin surface temperature of the individual, $r_{c}$ is the clothing resistance $\left(\mathrm{s} \mathrm{m}^{-1}\right)$, and $r_{a}$ is the boundary air resistance $\left(\mathrm{s} \mathrm{m}^{-1}\right) . T_{s k}$ was calculated based on the heat flow through the skin as:

$T_{s k}=T_{c}-\left(\frac{M r_{t}}{\rho C_{p}}\right)$

where $r_{t}$ is the resistance to heat flow of body tissue.

An individual's core temperature was estimated as (Campbell and Norman 1998; Kerslake 1972):

$T_{c}=36.5+0.0043 M$

Based on data presented by Fanger (1972), Brown and Gillespie (1986) suggest that body tissue resistance decreases with $M_{a}$ as:

$r_{t}=-0.1 M_{a}+65$

The boundary air resistance $\left(\mathrm{s} \mathrm{m}^{-1}\right)$ was calculated as (Campbell 1977):

$r_{a}=\frac{0.17}{\left(A \operatorname{Re}^{\mathrm{n}} \operatorname{Pr}^{0.33} \mathrm{k}\right)}$

where $R e$ is Reynolds number $\left(\frac{0.17 \mathrm{~V}}{v}\right), \operatorname{Pr}$ is Prandtl number (0.71), $V$ is the free stream air velocity, $v$ is the kinematic viscosity of air $\left(\sim 1.5 \times 10^{-5} \mathrm{~m}^{2} \mathrm{~s}^{-1}\right), \mathrm{k}$ is the thermal diffusivity of the air $\left(\sim 22 \times 10^{-6} \mathrm{~m}^{2} \mathrm{~s}^{-1}\right)$ and $\mathrm{A}$ and $\mathrm{n}$ are empirical constants derived from experiments on heat flow from cylinders: when $\operatorname{Re}<4,000, \mathrm{~A}=0.683$ and $n=0.466$; if $4,000<\mathrm{Re}<40,000, \mathrm{~A}=0.193$ and $n=0.618$; and if $\mathrm{Re}>40,000, \mathrm{~A}=0.0266$ and $n=0.805$ (Kreith and Black 1980). 
When wind velocities are greater than $0.7 \mathrm{~ms}^{-1}$, the resistance of clothing can be calculated as (Campbell 1977):

$r_{c}=r_{c o}\left(1-0.05(0.196 P)^{0.4} V^{0.5}\right)$

where $P$ is the air permeability of clothing fabric $\left(\mathrm{L} \mathrm{m}^{2} \mathrm{~s}^{-1}\right)$ and rco is the insulation value of clothing $\left(\mathrm{s} \mathrm{m}^{-1}\right)$ (Table 3 ). When wind velocities are less than $0.7 \mathrm{~m} \mathrm{~s}^{-1}$ :

$r_{c}=r_{c o}$

\section{Longwave radiation}

The long-wave or terrestrial radiation emitted by a person was estimated as:

$L=A_{\text {eff }} \varepsilon \sigma\left(T_{s f}+273.15\right)^{4}$

where $\varepsilon$ is the emissivity of human skin and clothing (0.95) and $\sigma$ is the Stefan-Boltzmann constant $\left(5.67 \times 10^{-8} \mathrm{~W} \mathrm{~m}^{-2}\right.$ $\left.\mathrm{K}^{-4}\right)$. $A_{\text {eff }}$ is a reduction factor based on the radiative area of a standing human (Kerslake 1972) that accounts for irregularities in the human body and interradiative exchange between the portions of the body which 'see' one another as part of the radiative environment. A value of 0.78 was applied for the walking and running subjects and a value of 0.70 was applied to the cyclists (Nielsen 1988, 1990). $T_{s f}$ is the surface temperature of an individual which is determined based upon the heat flow from the skin surface to the ambient environment as:

$T_{s f}=\left(\frac{T_{s k}-T_{a}}{r_{c}+r_{a}}\right) r_{a}+T_{a}$

\section{Evaporation}

Evaporative heat loss $\left(\mathrm{W} \mathrm{m}^{-2}\right)$ through perspiration was calculated as:

$E_{s}=0.42(M-58)$

Evaporative heat loss $\left(\mathrm{W} \mathrm{m}^{-2}\right)$ through skin diffusion was calculated as:

$E_{i}=\rho L_{v}\left(\frac{q_{s}-q_{a}}{r_{c v}+r_{a v}+r_{t v}}\right)$

where $q_{s}$ is the specific humidity ( $\mathrm{kg}$ of water vapor per $\mathrm{kg}$ of moist air) at skin temperature $T_{s k}$ and $q_{a}$ is the specific humidity at the air temperature $T_{a}, \rho$ is the density of air $\left(\sim 1.16 \mathrm{~kg} \mathrm{~m}^{-3}\right)$ and $L_{v}$ is the latent heat of vaporization $\left(2,442 \mathrm{~J} \mathrm{~g}^{-1}\right.$ at $\left.20^{\circ} \mathrm{C}\right)$. These values were calculated based on the following equation:

$q=0.622\left(\frac{e}{P_{a}-e}\right)$

where $e$ is the vapour pressure at $T_{s k}$ or $T_{a}$ and $P_{a}$ is the atmospheric pressure $(\mathrm{kPa})$ at the observation site. Fanger (1972) states this component of heat loss by vapour diffusion through the skin is part of the process of 'insensible' perspiration and is not subject to thermoregulatory control. The main barrier to this 'insensible' evaporative heat loss is the deeper layers of the epidermis - the resistance of which is very large in relation to the diffusion resistance of clothing and the boundary air layer. This deep skin tissue resistance to vapor transfer $\left(r_{t v}\right)$ is estimated to be $7.7 \times$ $10^{+3} \mathrm{~s} \mathrm{~m}^{-1}$ (Campbell and Norman 1998). The boundary
Table 3 Typical static insulation values for the clothing worn by subjects during the field tests

\footnotetext{
${ }^{\mathrm{a}}$ The clothing resistance expression $\mathrm{m}^{2}{ }^{\circ} \mathrm{CW}^{-1}$ (e.g. ISO

(2007)) is converted to $\mathrm{s} \mathrm{m}^{-1}$ by multiplying the clothing insulation values $\left(I_{c l}\right)$ by $\rho \mathrm{Cp}$, where $\rho$ is the density of air $\left(\mathrm{kg} \mathrm{m}^{-3}\right)$ and $\mathrm{Cp}$ is the specific heat of air ( $\mathrm{J} \mathrm{kg}^{-1}{ }^{\circ} \mathrm{C}^{-1}$ ).
}

\begin{tabular}{ll}
\hline Clothing ensemble/garment & $r_{\mathrm{c}}{ }^{\mathrm{a}}$ \\
\hline Track suit, socks, shoes & 140 \\
T-Shirt, long sleeve shirt, loose trousers, socks, shoes & 166 \\
Sweatshirt, sweatpants, socks, shoes & 144 \\
Long sleeve shirt, fitted trousers, socks, shoes & 116 \\
T-shirt, long pants, socks, shoes & 93 \\
Long sleeve shirt, walking shorts, socks, shoes & 99 \\
T-shirt, light athletic shorts, socks, shoes & 62 \\
T-shirt, regular walking shorts, socks, shoes & 77 \\
Tank top, shorts, socks, athletic shoes & 56 \\
Shirt, sweater, trousers, socks, shoes & 181 \\
T-shirt, long pants, socks shoes, jacket & 187 \\
Long-sleeve shirt, trousers or jeans, socks, shoes & 131 \\
Long sleeve shirt, long pants, socks, shoes, jacket & 205 \\
Short sleeve shirt, fitted trousers (including capris), socks, shoes & 93 \\
\hline
\end{tabular}


air layer resistance to vapor transfer is given by the expression:

$r_{a v}=0.92 r_{a}$

where 0.92 represents the difference in the molecular diffusivity of water vapour and heat (Brown and Gillespie 1986). Clothing vapour resistance $\left(r_{c v}\right)$ is assumed to equal clothing resistance $\left(r_{c}\right)$ (Brown and Gillespie 1986). The total evaporative loss $(E)$ is the sum of $E_{\mathrm{s}}+E_{i}$.

A maximum possible evaporation was calculated as:

$E_{m}=\rho L_{v}\left(\frac{q_{s}-q_{a}}{r_{c v}+r_{a v}}\right)$

The lower of $E$ or $E_{m}$ was input into the energy budget calculations, as it would be physically unreasonable for a person to sweat at a rate higher than that estimated in eq. 16, which assumes maximum transport of sweat through perspiration by negating the effect of tissue resistance.

\section{Radiation}

The radiation absorbed $\left(R_{R T}\right)$ was calculated using the a cylindrical radiation thermometer (CRT). The methods outlined by Kenny et al. (2008) were used to convert the CRT measurements to the radiation absorbed by a human.

\section{Translating the COMFA budget values}

The COMFA budget is calculated based upon the energy budget inputs (Metabolic Heat Production and Radiation Absorbed) and the outputs (Convection, Evaporation, and Long-wave Radiation Emitted) as:

$B=M+R_{R T}-C-E-L$

Based upon research conducted by Harlan et al. (2006), which related a human thermal comfort index (developed from the COMFA model) to the NOAA's Heat Index, a 7point scale for predicted thermal sensation (PTS) was developed (Table 4).

Table 4 Seven-point scale for the predicted thermal sensation ratings that were applied to the COMFA budget output

\begin{tabular}{lll}
\hline Sensation ratings & Budget $\left(\mathrm{Wm}^{-2}\right)$ & Description \\
\hline-3 & $\leq-201$ & Cold \\
-2 & -200 to -121 & Cool \\
-1 & -51 to -120 & Slightly cool \\
0 & -50 to +50 & Neutral \\
1 & 51 to +120 & Slightly warm \\
2 & +121 to +200 & Warm \\
3 & $\geq+201$ & Hot \\
\hline
\end{tabular}

\section{Results}

A total of 12 field test were conducted during the morning, afternoon, and early evening hours under clear, partly cloudy and overcast skies (Table 5). Air temperature, ambient vapor pressure, and wind speed values ranged from approximately $13-29^{\circ} \mathrm{C}, 0.64-2.05 \mathrm{kPa}$, and $1.7-$ $4.8 \mathrm{~m} \mathrm{~s}^{-1}$, respectively. The 5-min average incoming shortwave radiation values ranged from approximately 120 to $720 \mathrm{~W} \mathrm{~m}^{-2}$, and the atmospheric long-wave radiation values from 280 to $400 \mathrm{~W} \mathrm{~m}^{-2}$.

\section{Factors affecting the subjects' actual thermal sensation (ATS) votes}

A multiple regression model for ordinal data was used to test the dependence of the ATS votes on a set of predictors including: sex, activity, age, weight, clothing permeability and insulation, air temperature, CRT temperature, relative humidity, incoming and outgoing short- and long-wave radiation, wind velocity, activity speed, and metabolic activity rate (Table 6). The model results suggest that the ATS votes were significantly dependent upon sex, air temperature, CRT temperature, incoming and outgoing short-wave radiation, outgoing long-wave radiation, wind speed, and metabolic activity rate.

Figure 1 displays the frequency of the ATS responses distributed by the subjects' sex. The results reveal that more females choose an ATS rating +2 (warm) and +3 (hot), while more males choose the categories +1 (slightly warm) and -1 (slightly cool). Pearson correlation was used to further assess the relationship between each of the scalar variables identified as contributing significantly to the ATS votes in the multiple regression model (Table 7). Air temperature, CRT temperature, outgoing long-wave radiation, and metabolic activity rate were significantly positively correlated (Pearson correlation 0.4 ) with the ATS scores. There was no significant relationship for wind speed and incoming and outgoing short-wave radiation when these parameters were assessed individually against the ATS votes.

Correlation analysis was also conducted to assess the effect of exercise intensity, as determined by the subjective rate of perceived exertion (RPE) scores and their heart rates, on the ATS votes. The ATS votes were significantly positively correlated with the subjects' RPE (correlation coefficient $=0.617, P<0.01$ ) and heart rates (Pearson's correlation $=0.504, P<0.01)$, suggesting that as the subject's exercise intensity increased, their ATS ratings were also likely to increase.

The correlation was not particularly strong between the ATS votes and any one of the above predictors, 
Table 5 Summary of the meteorological conditions recorded on-site for each test day ${ }^{\mathrm{a}}$

${ }^{a} T_{a}$ (air temperature), $e$ (ambient vapor pressure), $V$ (wind speed), $K_{t}$ (direct and diffuse incoming short-wave radiation), and $L_{a}$ (atmospheric long-wave radiation), expressed as the mean over the test period.

\begin{tabular}{lllllll}
\hline Date & Time(hours $)$ & $T_{a}\left({ }^{\circ} \mathrm{C}\right)$ & $\mathrm{e}(\mathrm{kPa})$ & $V\left(\mathrm{~m} \mathrm{~s}^{-1}\right)$ & $K_{t}\left(\mathrm{Wm}^{-2}\right)$ & $L_{a}\left(\mathrm{Wm}^{-2}\right)$ \\
\hline $30 / 10 / 2006$ & $1350-1420$ & 13.4 & 0.64 & 1.8 & 399 & 281 \\
$13 / 07 / 2007$ & $1225-1255$ & 18.3 & 1.09 & 4.8 & 480 & 346 \\
$15 / 07 / 2007$ & $1435-1505$ & 21.0 & 1.13 & 4.2 & 552 & 374 \\
$30 / 07 / 2007$ & $0945-1015$ & 23.7 & 1.55 & 1.8 & 590 & 347 \\
$31 / 07 / 2007$ & $1815-1845$ & 29.2 & 2.05 & 2.0 & 134 & 395 \\
$15 / 08 / 2007$ & $1740-1810$ & 22.6 & 1.41 & 2.3 & 118 & 376 \\
$19 / 08 / 2007$ & $1310-1340$ & 19.0 & 0.99 & 1.7 & 499 & 362 \\
$28 / 08 / 2007$ & $1140-1210$ & 24.0 & 1.64 & 2.9 & 751 & 361 \\
$30 / 08 / 2007$ & $1040-1110$ & 17.7 & 1.46 & 4.1 & 632 & 352 \\
$13 / 09 / 2007$ & $1350-1420$ & 17.9 & 1.20 & 4.1 & 556 & 341 \\
$18 / 09 / 2007$ & $1345-1415$ & 22.2 & 1.16 & 3.3 & 716 & 342 \\
$04 / 10 / 2007$ & $1350-1420$ & 23.9 & 0.96 & 3.0 & 656 & 329 \\
\hline
\end{tabular}

suggesting that a complex interaction of individual and microclimatic variables contributes to thermal comfort. This result provides further rationale for applying an energy balance approach to assessing thermal comfort, which allows for the simultaneous integration of many interacting variables.
Comparing the actual and predicted thermal sensation (TS) scores

Figure 2 displays the distribution of the actual thermal sensation votes (ATS) given by the participants during the field testing. The results show a normal distribution, with

Table 6 Ordinal regression model assessing the dependence of the subjects' actual thermal sensation votes on various recorded predictors

\begin{tabular}{|c|c|c|c|}
\hline & Estimate & SE & Significance \\
\hline Age (years) & .014 & .020 & .496 \\
\hline Weight $(\mathrm{kg})$ & .016 & .017 & .343 \\
\hline$P\left(f t^{3} f t^{-2} \min ^{-1}\right)$ & -.004 & .002 & .144 \\
\hline$r_{c o}\left(\mathrm{~s} \mathrm{~m}^{-1}\right)$ & .005 & .007 & .495 \\
\hline$T_{a}\left({ }^{\circ} \mathrm{C}\right)$ & -.898 & .287 & $.002^{\mathrm{a}}$ \\
\hline$T_{r t}\left({ }^{\circ} \mathrm{C}\right)$ & 1.357 & .311 & $.000^{\mathrm{a}}$ \\
\hline RH (\%) & .014 & .024 & .575 \\
\hline$V\left(\mathrm{~m} \mathrm{~s}^{-1}\right)$ & .516 & .207 & $.013^{\mathrm{a}}$ \\
\hline$M_{a}\left(\mathrm{~W} \mathrm{~m}^{-2}\right)$ & .009 & .002 & $.000^{\mathrm{a}}$ \\
\hline$K_{t}\left(\mathrm{~W} \mathrm{~m}^{-2}\right)$ & -.024 & .005 & $.000^{\mathrm{a}}$ \\
\hline$K_{r}\left(\mathrm{~W} \mathrm{~m}^{-2}\right)$ & .097 & .022 & $.000^{\mathrm{a}}$ \\
\hline$L_{a}\left(\mathrm{~W} \mathrm{~m}^{-2}\right)$ & -.012 & .013 & .353 \\
\hline$L_{g}\left(\mathrm{~W} \mathrm{~m}^{-2}\right)$ & .010 & .005 & $.034^{\mathrm{a}}$ \\
\hline$V_{a}\left(\mathrm{~m} \mathrm{~s}^{-1}\right)$ & .205 & .198 & .301 \\
\hline Sex & 1.178 & .330 & $.000^{\mathrm{a}}$ \\
\hline Activity & 1.339 & .904 & $.138-.417$ \\
\hline Goodness of fit & Chi-square & $d f$ & Significance \\
\hline Pearson & $1,617.229$ & 1,871 & 1.000 \\
\hline Deviance & 903.952 & 1,871 & 1.000 \\
\hline Pseudo & $R$-square & & \\
\hline Cox and Snell & .482 & & \\
\hline Nagelkerke & .508 & & \\
\hline McFadden & .222 & & \\
\hline
\end{tabular}

${ }^{\text {a }}$ Significant at a $P<0.05$ level 


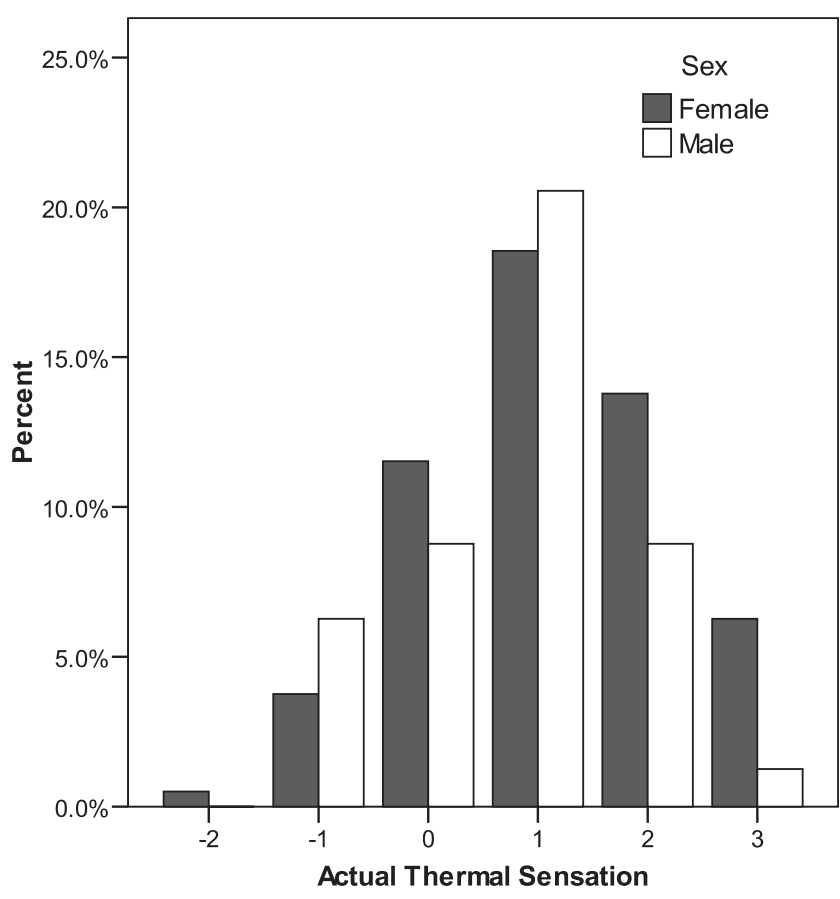

Fig. 1 Frequency distribution for the subjects' ATS by sex. The votes were made along a 7 -point scale from -3 (cold) to +3 (hot)

the majority of votes $(82 \%)$ received in the region 0 (neutral) $\leq$ ATS $\geq+2$ (warm). The category +1 (slightly warm) received the most votes $(39.1 \%)$, while the categories 0 (neutral) and +2 (warm) were almost evenly split with $20.3 \%$ and $22.6 \%$ of the votes, respectively. Few of the votes were given for the categories +3 (hot) $(7.5 \%),-1$ (slightly cool) (10.0\%) and -2 (cool) $(0.5 \%)$.

Figure 3 displays the distribution for the predicted thermal sensation (PTS) votes as estimated using the COMFA model for the field testing periods. Similar to the ATS votes, the majority of votes $(84.7 \%)$ were predicted in the regions 0 (neutral) $\leq$ ATS $\geq+2$ (warm). However, the PTS votes did not display a normal distribution. In contrast

Table 7 Correlation analysis of the ATS votes with air temperature, CRT temperature, incoming and outgoing short-wave radiation, outgoing long-wave radiation, wind speed, and metabolic activity rate

\begin{tabular}{llll}
\hline Variable & Pearson correlation & Significance & $n$ \\
\hline $\mathrm{T}_{\mathrm{a}}\left({ }^{\circ} \mathrm{C}\right)$ & .412 & $.000^{\mathrm{a}}$ & 399 \\
$\mathrm{~T}_{\mathrm{rt}}\left({ }^{\circ} \mathrm{C}\right)$ & .416 & $.000^{\mathrm{a}}$ & 399 \\
$\mathrm{M}_{\mathrm{a}}\left(\mathrm{W} \mathrm{m}{ }^{-2}\right)$ & .419 & $.000^{\mathrm{a}}$ & 399 \\
$\mathrm{~K}_{\mathrm{t}}\left(\mathrm{W} \mathrm{m}{ }^{-2}\right)$ & -.005 & .921 & 399 \\
$\mathrm{~K}_{\mathrm{r}}\left(\mathrm{W} \mathrm{m}{ }^{-2}\right)$ & -.115 & .021 & 399 \\
$\mathrm{~L}_{\mathrm{g}}\left(\mathrm{W} \mathrm{m}^{-2}\right)$ & .352 & $.000^{\mathrm{a}}$ & 399 \\
$\mathrm{~V}\left(\mathrm{~m} \mathrm{~s}{ }^{-1}\right)$ & -.014 & .776 & 399 \\
\hline
\end{tabular}

${ }^{\text {a }}$ Significant at a $P<0.05$ level

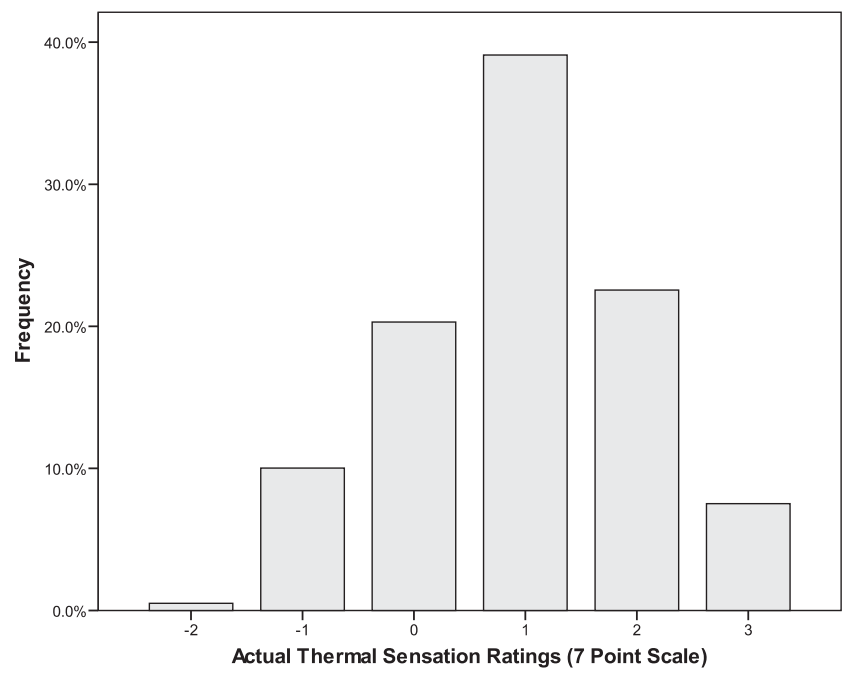

Fig. 2 Actual thermal sensation votes (ATS) of the participants during field testing given along the 7-point thermal sensation scale

to the ATS votes, the majority of the PTS votes were received in the 0 (neutral) $(36.8 \%)$ and +2 (warm) $(29.8 \%)$ categories, while category +1 (slightly warm) was predicted $18.1 \%$ of the time. Few of the votes were predicted for the categories +3 (hot) $(11.3 \%),-1$ (slightly cool) $(3.0 \%)$ and -3 (cold) $(1.0 \%)$.

Figure 4 displays the range of COMFA budget values plotted against each of the ATS vote categories during the field testing periods ( $n=399$ responses). This approach allows for a clear assessment of the budget ranges associated with the responses for each of the ATS categories. It is helpful to examine the interquartile range (IQR) between the 75th and 25th percentile (the range of the middle $50 \%$ of the data) and the median budget for each category, which are less affected by outliers or extremes than the arithmetic mean. The median budget values for

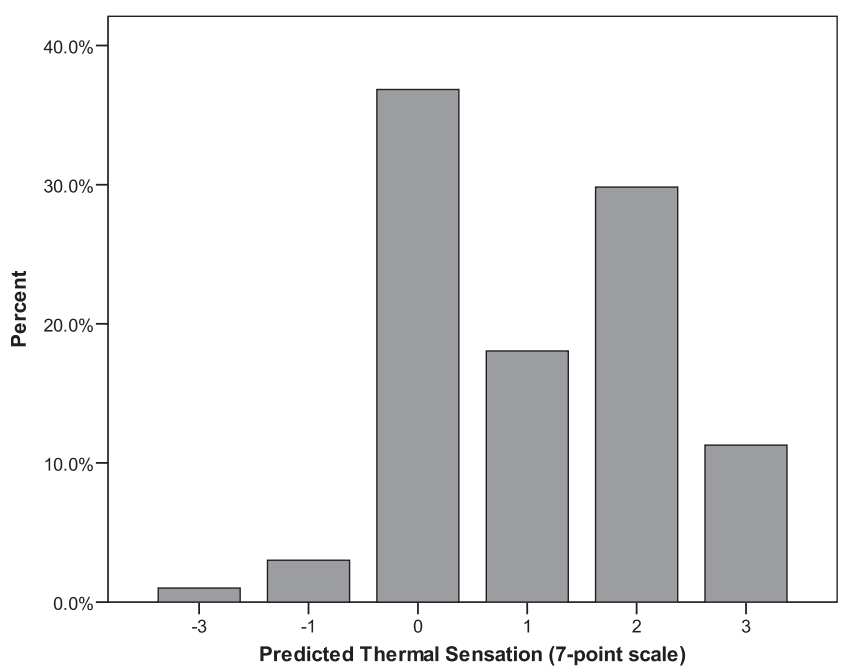

Fig. 3 Predicted thermal sensation votes during the field testing 


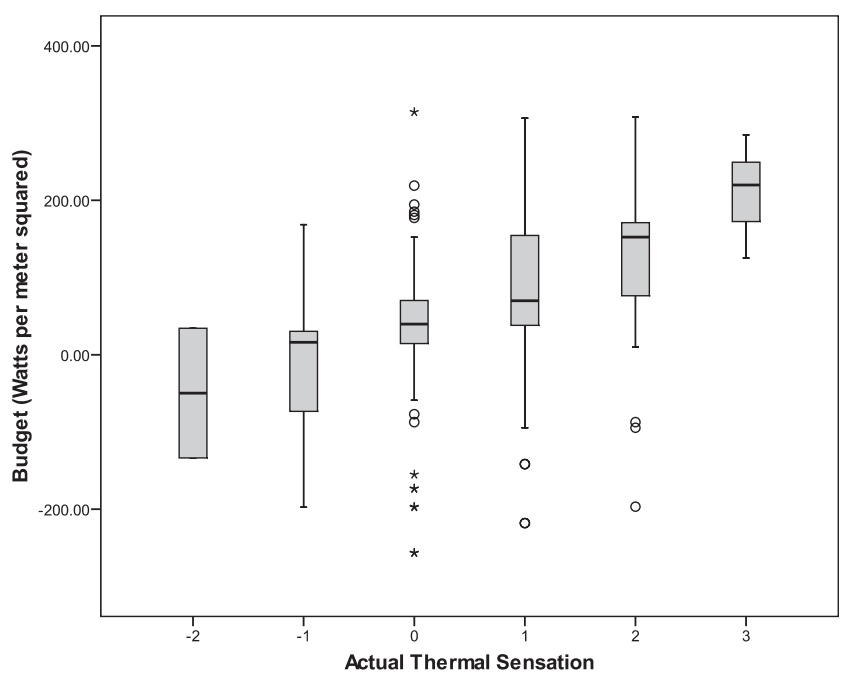

Fig. 4 Stem and leaf box plot displaying the range of the COMFA budget values for each of the actual thermal sensation ratings. The length of each box is indicated by the interquartile range (IQR) between the 25th and 75th percentile. Outliers (values 1.5-3 IQRs from the end of the box) are marked by ${ }^{\circ}$, and $*$ denotes extreme values (values in excess of 3 IQRs from the end of the box)

each ATS category were: $-2(\mathrm{cool})=-50 \mathrm{~W} \mathrm{~m}^{-2} ;-1$ (slightly cool) $=16 \mathrm{~W} \mathrm{~m}^{-2} ; 0$ (neutral) $=40 \mathrm{~W} \mathrm{~m}^{-2} ;+1$ (slightly warm) $=70 \mathrm{~W} \mathrm{~m}^{-2}$; $+2 \quad$ (warm $)=152 \mathrm{~W} \mathrm{~m}^{-2}$; and +3 (hot $)=219 \mathrm{~W} \mathrm{~m}^{-2}$. It should be clearly noted that only 2 data points are available for the category -2 (cool), therefore caution must be used when interpreting the results for this category. The IQR was lowest for the categories 0 (neutral) $\left(59 \mathrm{~W} \mathrm{~m}^{-2}\right)$ and +3 (hot) $\left(72 \mathrm{~W} \mathrm{~m}^{-2}\right)$ and greatest for the categories +1 (slightly warm) $\left(149 \mathrm{~W} \mathrm{~m}^{-2}\right)$ and -1 (slightly cool) $\left(116 \mathrm{~W} \mathrm{~m}^{-2}\right)$. There was a clear overlap

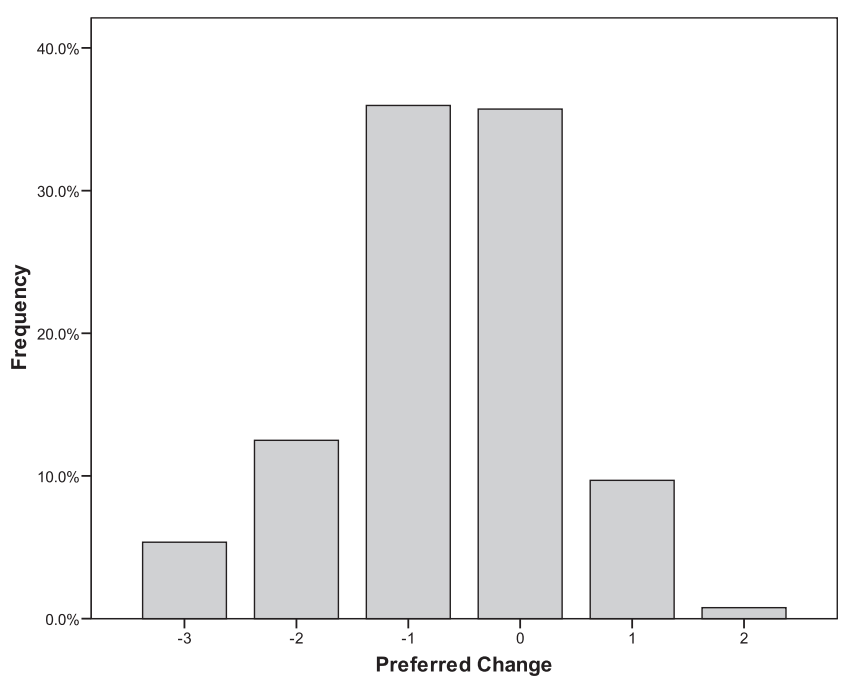

Fig. 5 Frequency distribution for the subjects' preferred change to the thermal environment votes between the IQR for all categories with the exception of +3 (hot). In a small number of cases $(6 \%)$, the COMFA model substantially under- or overestimated the ATS votes, as indicated by the outlier and extreme values outside the IQR. The outliers are values 1.5-3 IQRs from the end of the box and the extreme values are values in excess of 3 IQRs from the end of the box. The greatest number of outlier and extreme values were apparent in the 0 (neutral) ATS category.

Spearman's rho was used to assess the general trend in the strength of the relationship between ATS and PTS. It was appropriate as it is used to measure associations for ordinal data based on the rank positions of the data rather than the actual numeric values (Isaac and Michael 1997). The results suggest that the ATS and PTS votes were significantly positively correlated (correlation coefficient $=0.574, P<0.01$ ).

Although the strength of the relationship between the predicted and actual thermal sensation votes was determined to be significant, there were discrepancies between the PTS and ATS votes. The predicted and actual thermal sensation votes were equal $36 \%$ of the time. The model overestimated the actual thermal sensation ratings by one 'sensation' category $30 \%$ of the time, and underestimated the actual thermal sensation ratings by one 'sensation' category $23 \%$ of the time. Approximately $7 \%$ of the votes were under- or overestimated by two 'sensation' categories, and $4 \%$ were under- or overestimated by three sensation categories.

Figure 5 shows the frequency of response for the subjects' rating of their preferred change (PC) to the thermal environment. The majority of votes were equally distributed between -1 (prefer to be slightly cooler) and 0 (prefer no change) (36\%). Far fewer votes were received for -2 (preferred to be cooler) $(13 \%),+1$ (preferred to be slightly warmer) $(10 \%),-3$ (preferred to be much cooler) $(5 \%)$ and +2 (preferred to be warmer) $(1 \%)$. There were no votes received for +3 (preferred to be much warmer).

There was a significant negative correlation between the PC votes and the ATS votes (correlation coefficient= -0.827 ), suggesting as the subjects felt warmer, they were likely to vote that they preferred to be cooler. However, many of the subjects $(35 \%)$ with an ATS vote of +1 (slightly warm) had a PC vote of 0 (preferred no change) and of those with an ATS vote of +2 (warm), the PC votes were almost evenly distributed between -1 (prefer to be slightly cooler) (48\%) and -2 (prefer to be cooler) $(45 \%)$. In addition, although the majority of respondents $(70 \%)$ with an ATS vote of -1 (slightly cool) had a PC vote of +1 (slightly warmer), $30 \%$ of the respondents had a $\mathrm{PC}$ vote of 0 (preferred no change). These results suggest that many subjects were not unsatisfied with a thermal environment that they rated as slightly warm or slightly cool. 


\section{Discussion}

\section{Comparing ATS to PTS}

The results revealed a normal distribution in the responses of the ATS votes, with the category +1 (slightly warm) receiving the majority of the votes by the respondents. In an extensive study of in excess of 9,000 participants using outdoor spaces in seven different European cities, Nikolopoulou and Lykoudis (2006) also found a normal distribution in ATS votes, with the highest distribution of votes centered around the 'neutral' (0) sensation category. In a previous study of in excess of 1,000 participants, Nikolopoulou et al. (2001) found the greatest frequency of votes was received for the category +1 (warm), which they attributed to a slight sampling bias to warmer temperature days. Both of these studies applied a 5-point ATS scale and largely involved subjects performing activity at low metabolic rates (i.e., sitting or standing). In the present study, it is likely that relatively warm distribution of ATS votes [approximately $80 \%$ of the ATS and PTS votes were received in the 0 (neutral) to +2 (warm) categories] is a reflection of the fact that the participants were performing moderate to vigorous physical activity.

Although there was discrepancy between the ATS and PTS votes in the present study, the results revealed a significant positive correlation between the ATS and PTS votes. The association between the ATS and PTS votes was not as strong as the results presented by Brown and Gillespie (1986) in their original assessment of the COMFA model. There was considerable overlap between the COMFA budget ranges for each comfort category, especially between the categories 0 (neutral) and -1 (slightly cool) $/+1$ (slightly warm), and the categories +1 (slightly warm) and +2 (warm), making it difficult to clearly delineate the PTS thermal sensation categories presented in Table 4. In addition, there were a number of outlier and extreme PTS values predicted by the COMFA model under the range of conditions specified in the present study, especially in the ranges 0 (neutral) to +2 (warm).

Despite these discrepancies, the COMFA model predicted the ATS of outdoor recreation users performing moderate to vigorous physical activity within \pm 1 thermal sensation vote $89 \%$ of the time. "There will naturally be a certain variance in the thermal sensations of a group of persons exposed to the same environment (Fanger 1972, p.128)." Inter-individual variation in subjective responses are common in thermal comfort studies, especially with increased physical activity (Gavhed and Holmer 1996). An individual's thermal sensation depends on a number of factors, including miroclimatic conditions, activity rates, and clothing characteristics. Psychological factors associated with expectation, thermal history, environmental stimulation, time of exposure, and choice can greatly impact an individual's thermal sensation (Nikolopoulou et al. 2001; Nikolopoulou and Steemers 2003; Nikolopoulou and Lykoudis 2006; Spagnolo and de Dear 2003a; Thorsson et al. 2004). Hoppe (2002) notes that the expectation of specific thermal conditions contributes greatly to a user's subjective assessment of the thermal environment. In a recent study, Knez and Thorsson (2006) also found that cultural differences influenced the thermal sensation votes between users of urban spaces in Sweden 20 and Japan.

Various outdoor thermal comfort studies have evaluated the performance of the PMV (Nikolopoulou et al. 2001; Nikolopoulou and Lykoudis 2006; Thorsson et al. 2004) and equivalent temperature models (e.g. OUTSET*, PET) (Spagnolo and de Dear 2003a; Knez and Thorsson 2006) in outdoor environments. Due to the inherent differences between these approaches and the COMFA model, it is therefore difficult to directly compare the results of the present study to past research with accuracy. The results of the present study do support the findings of past research, which suggest that energy balance models do not fully describe the variance between ATS and PTS votes, and that additional factors, such as those related to psychological adaptation, are likely to affect an individual's thermal sensation.

Analysis of the participants' perceived change votes demonstrated that subjects often did not object to having a thermal sensation outside the limits of neutral, thus supporting past findings that people in outdoor spaces appear to have a wide range of acceptability (Johansson and Emmanuel 2006; Spagnolo and de Dear 2003a; Ahmed 2003; Nikolopoulou et al. 2001). Spagnolo and de Dear (2003a, pp.735-736) recommend that wider comfort limits be determined for use in outdoor environments, in order to account for this variability as, "...the expectation that the outdoor environment is much more variable over space and time than the indoor environment, and the perceived lack of control over the outdoor environment, leads to a significant widening of the comfort zones in outdoor environments."

It is expected that the range of neutral conditions is likely to be greater for athletes as compared to sedentary individuals (Spagnolo and de Dear 2003b), as their motivation to continue exercise tends to exceed feelings of thermal discomfort (Nikolopoulou and Lykoudis 2006). From the results of the present study, it may be concluded that many participants did not mind feeling slightly warm or slightly cool, and that the corresponding 'comfort zone' could be extended from $-120 \mathrm{~W} \mathrm{~m}^{-2} \leq$ BUDGET $\geq$ $+120 \mathrm{~W} \mathrm{~m}^{-2}$, which is much in excess of that proposed in the original analysis of the COMFA model proposed by Brown and Gillespie (1986) (i.e. $-50 \mathrm{~W} \mathrm{~m}^{-2} \leq \mathrm{BUD}$ $\mathrm{GET} \geq+50 \mathrm{~W} \mathrm{~m}^{-2}$ ). 
The original COMFA model (Brown and Gillespie 1986) is based upon a 5-point predicted scale for thermal sensation. In order to apply the COMFA model to the widely applied ASHRAE 7- point scale for thermal sensation, a new 7-point PTS scale (adapted from Harlan et al. (2006)) was evaluated in this study. Although further research is recommended to confirm the appropriateness of this scale in a variety of outdoor environments, the current study suggests that it provides an effective representation of the ASHRAE 7-point scale for ATS. However, there is question as to whether a 7-point scale provides an adequate range of choice for users of outdoor spaces, as it was developed for application indoors, where the limits of exposure are much narrower (Spagnolo and de Dear 2003a).

The ATS votes were significantly dependent upon sex, air temperature, CRT temperature, incoming and outgoing short-wave radiation, outgoing long-wave radiation, wind speed, and metabolic activity rate, although the correlations of the individual parameters to the ATS votes were relatively weak, suggesting that a complex interaction of individual and microclimatic variables contributes to thermal comfort. This result provides further support for applying an energy balance approach to assessing outdoor thermal comfort, which allows for the simultaneous integration of many interacting variables. Nikolopoulou and Lykoudis (2006) also found similar correlations between globe temperature (used as a measure of radiation) and air temperature and ATS votes in their extensive study of outdoor spaces in Europe.

In the present study, females displayed a bias to an ATS of +2 (warm) to +3 (hot) and the males were more likely to choose within the more moderate ATS zone of -1 (slightly warm) to +1 (slightly warm). Although a similar trend was discovered in an indoor thermal comfort study by Erlandson et al. (2003), this gender-related effect on thermal sensation has not been adequately examined in outdoor thermal comfort studies and warrants additional attention. The relatively small sample size $(n=27)$ and fact that slightly more females $(n=16)$ than males $(n=11)$ were tested may have also contributed to this finding in the present study.

ATS votes were also positively correlated with the subjects' heart rates and RPE. Heart rate provides a reliable and valid indicator of physical strain caused by a variety of sources, such as activity, static exertion, thermal strain, and psychological stress (Parsons 2003; Kang et al. 2003). Heart rate is strongly associated with oxygen uptake $\left(\mathrm{VO}_{2}\right)$; any given increase in $\mathrm{VO}_{2}$ is normally associated with an increased heart rate, which reflects the circulatory adjustments required to meet increases in metabolic demand (Kang et al. 2003). RPE provides a subjective evaluation of strain, effort, discomfort, and/or fatigue during exercise
(Batte et al. 2003; Dunbar et al. 1992). The 15-point scale of RPE (Borg 1982) applied in this study is commonly used as a prescriptive guide for exercise due to its proven reliability and ease of application (Lamb et al. 1999). In many cases, because of its ease of use, RPE is considered to be a more desirable tool than monitoring heart rate or metabolic rate (Batte et al. 2003). RPE has been found to be strongly correlated with physiological variables such as heart rate, $\mathrm{VO}_{2}$, and blood lactate. Any physiological variable linearly related to exercise intensity tends to parallel perceptual ratings obtained from the Borg scale (Noble et al. 1983).

The positive correlation between ATS votes and the subjects' heart rate and RPE votes suggests that, as these factors increased with exercise intensity, the subjects' ATS ratings were also likely to increase. This increase in ATS with exercise intensity was also noted by Maw et al. (1993), Gavhed and Holmer (1996), and Virokannas (1996). For example, Maw et al. (1993) exposed athletes performing 30 minutes of steady state exercise to hot $\left(40^{\circ} \mathrm{C}\right)$, thermoneutral $\left(24^{\circ} \mathrm{C}\right)$, and cool $\left(8^{\circ} \mathrm{C}\right)$ conditions in an environmental chamber. It was concluded that subjects felt worse, had significantly higher heart rates and skin temperatures, and increased RPE ratings under hot conditions than in the neutral or cool conditions. Although working at the same exercise intensity, subjects also had comparatively low thermal sensation ratings in the thermo-neutral and cool conditions as compared to the hot environment.

There is great spatial and temporal variability in outdoor environments, and it is very difficult to quantify precisely the factors contributing to outdoor thermal comfort. It would be nearly impossible to standardize all of the thermophysiological, microclimatic, and psychological factors which contribute to outdoor thermal comfort, while maintaining a sense of 'real-life' external validity in outdoor thermal comfort research. It is clear from the present study that ATS is influenced beyond physiological and microclimatic factors, and additional research into the effect of psychological aspects, such as expectancy and perceived control on users performing physical activity, is recommended. Past outdoor thermal comfort research has also found a seasonal skewing of ATS votes towards the cool end of the scale in winter and the warm end of the scale in the summer, due to factors such as adaptation, recent experience, and expectation (Nikolopoulou and Lykoudis 2006; Spagnolo and de Dear 2003a). It is therefore important to extend future studies to consider a wider range of conditions in all seasons to examine if similar trends in seasonal differences in neutrality are applicable to users performing physical activity.

Much recent research attention has been focussed on the effects of wind and body movement on clothing insulation and vapour resistance. The COMFA model as presented 
does not consider the combined effects of wind and activity speed. Research has concluded that activity and wind can reduce clothing insulation in excess of $50 \%$ and vapour resistance by over $80 \%$, in comparison to the static resistance values (Havenith et al. 2002). Various clothing insulation and vapour resistance correction factors have been proposed (Bouskill et al. 2002; Havenith et al. 2002; Holmer et al. 1999; Parsons et al. 1999), although many are limited to wind speeds less than $3.5 \mathrm{~m} \mathrm{~s}^{-1}$ and activity speeds less than $1.2 \mathrm{~m} \mathrm{~s}^{-1}$. Havenith et al. (2002) specifically suggest that outdoor thermal comfort models be improved to consider the dynamic effects of activity and wind speed on clothing. Clothing insulation is an important parameter within the COMFA model, as it greatly effects the heat and moisture transfer between the body and the surrounding environment. Although the COMFA model provides a simplified equation (e.g., eq. 8) for clothing insulation, future research is recommended to examine the combined effect of activity and wind speed on thermal comfort, by integrating recent recommendations on clothing insulation and vapour resistance into the COMFA outdoor thermal comfort model.

\section{Conclusion}

By examining the thermal comfort of outdoor recreation users, this study has addressed an important research gap. The following can be concluded from the present study:

- Given the fact that there is likely to be variation in subjective responses to thermal sensation in outdoor environments, the COMFA model performed quite well, predicting the ATS of subjects performing moderatevigorous physical activity within \pm 1 thermal sensation vote $89 \%$ of the time. However, there were some discrepancies between the ATS and PTS votes, and it is likely that additional factors related to psychological adaptation and expectancy contributed to the participants' thermal sensation votes.

- The model substantially over- or underestimated the heat and moisture exchange between the human body and the ambient environment in $6 \%$ of the cases. Therefore, it is recommended that a sensitivity analysis be conducted to clearly identify how changes to each of the COMFA model inputs (i.e., air temperature, CRT temperature, relative humidity, clothing insulation and permeability, wind velocity, and metabolic activity) affect the model outputs. This analysis will clearly identify where the model produces erroneous estimates the heat and moisture exchanges between the human body and the ambient environment when athletes are performing moderate to vigorous physical activity.
- Under the conditions specified in this study, subjects performing moderate-vigorous physical activity were likely to have an ATS on the warm end of the thermal sensation scale (0 (neutral) to +2 (warm)).

- The subjects' heart rate and RPE were positively correlated with their ATS votes, suggesting that as exercise intensity increased, the ATS votes were also likely to increase.

- Many subjects did not object to having a thermal sensation outside of the limits of neutral, and it is likely that users performing physical activity have a broader comfort zone than sedentary users.

- A complex interaction of individual and microclimatic variables contributed to the subjects' thermal sensation, providing further rationale for applying an energy balance approach to assessing outdoor thermal comfort. The ATS votes were significantly correlated with sex, air temperature, CRT temperature, radiation, wind speed, and metabolic activity rate.

Outdoor thermal comfort models have been under scrutiny due to their inability to accurately predict subjective assessments of thermal sensation. It is impossible to satisfy every user in an outdoor space, and there will always be some variation between actual and predicted thermal sensation votes in outdoor environments. The results of the present study suggest that the COMFA model performed well, effectively predicting the thermal sensation of users performing physical activity in the majority of cases. In spite of the model's performance, there are obvious shortcomings in the COMFA model, especially related to the quantification of clothing insulation and vapour resistance. Part B of this research project, which follows in this issue will address these shortcomings to improve the COMFA model for application on subject performing outdoor activity.

\section{List of Symbols and Abbreviations}

$A_{\text {eff }} \quad$ Effective area factor

ATS Actual thermal sensation

$B \quad$ COMFA budget value $\left(\mathrm{W} \mathrm{m}^{-2}\right)$

$C$ Convective heat losses from a person $\left(\mathrm{W} \mathrm{m}^{-2}\right)$

$C R T$ Cylindrical radiation thermometer

$D \quad$ Diameter of a cylinder (m)

$E \quad$ Evaporative heat losses from a person $\left(\mathrm{W} \mathrm{m}^{-2}\right)$

$E_{i} \quad$ Evaporative heat loss through diffusion $\left(\mathrm{W} \mathrm{m}^{-2}\right)$

$E_{m} \quad$ Maximal evaporative heat loss $\left(\mathrm{W} \mathrm{m}^{-2}\right)$

$E_{s} \quad$ Evaporative heat loss through sweat $\left(\mathrm{W} \mathrm{m}^{-2}\right)$

$e \quad$ Ambient vapor pressure $(\mathrm{kPa})$

$e_{s} \quad$ Saturation vapor pressure $(\mathrm{kPa})$

$e_{s k} \quad$ Vapour pressure at the skin surface (kPa)

$f \quad$ Heat loss consumed through breathing $\left(\mathrm{W} \mathrm{m}^{-2}\right)$

$H R_{\max }$ Maximum heart rate 
$\mathrm{K} \quad$ Thermal diffusivity of air $\left(\sim 22 \times 10^{-6} \mathrm{~m}^{2} \mathrm{~s}^{-1}\right)$

$K_{t} \quad$ Total incoming solar radiation $\left(\mathrm{W} \mathrm{m}^{-2}\right)$

$L \quad$ Long-wave radiation emitted from a person $\left(\mathrm{W} \mathrm{m}^{-2}\right)$

$L_{a} \quad$ Atmospheric longwave radiation $\left(\mathrm{W} \mathrm{m}^{-2}\right)$

$L_{g} \quad$ Long-wave radiation emitted from the ground surface $\left(\mathrm{W} \mathrm{m}^{-2}\right)$

$L_{v} \quad$ Latent heat of vaporization $\left(\mathrm{J} \mathrm{kg}^{-1}\right)$

$M \quad$ Metabolic heat generated by a person $\left(\mathrm{W} \mathrm{m}^{-2}\right)$

$M_{a} \quad$ Metabolic activity rate $\left(\mathrm{W} \mathrm{m}^{-2}\right)$

$P \quad$ Clothing permeability $\left(1 \mathrm{~m}^{2} \mathrm{~s}^{-1}\right)$

$P_{a} \quad$ Atmospheric pressure $(\mathrm{kPa})$

$P C \quad$ Perceived change in thermal sensation

PET Physiological equivalent temperature $\left({ }^{\circ} \mathrm{C}\right)$

$P M V \quad$ Predicted mean vote

PTS Predicted thermal sensation

$\mathrm{Pr} \quad$ Prandtl number

$q_{a} \quad$ Specific humidity at air temperature ( $\mathrm{kg}$ of water vapour/kg moist air)

$q_{s} \quad$ Specific humidity at skin temperature ( $\mathrm{kg}$ of water vapour $/ \mathrm{kg}$ moist air)

$R \quad$ Radiation absorbed $\left(\mathrm{W} \mathrm{m}^{-2}\right)$

Re Reynolds number

RH Relative humidity (\%)

$R P E \quad$ Rate of perceived exertion

$r_{a} \quad$ Boundary air layer resistance $\left(\mathrm{s} \mathrm{m}^{-2}\right)$

$r_{a v} \quad$ Boundary air layer resistance to water vapour $\left(\mathrm{s} \mathrm{m}^{-1}\right)$

$r_{c} \quad$ Clothing resistance $\left(\mathrm{s} \mathrm{m}^{-1}\right)$

$r_{c o} \quad$ Clothing resistance $\left(\mathrm{s} \mathrm{m}^{-1}\right)$ (static no reduction factor)

$r_{c v} \quad$ Clothing vapour resistance $\left(\mathrm{s} \mathrm{m}^{-1}\right)$

$r_{t} \quad$ Body tissue resistance $\left(\mathrm{s} \mathrm{m}^{-1}\right)$

$r_{t v} \quad$ Deep tissue resistance to vapor transfer $\left(\sim 7700 \mathrm{~s} \mathrm{~m}^{-1}\right)$

$T_{a} \quad$ Air temperature $\left({ }^{\circ} \mathrm{C}\right)$

$T_{c} \quad$ Core temperature $\left({ }^{\circ} \mathrm{C}\right)$

$T_{c l} \quad$ Outer clothing surface temperature $\left({ }^{\circ} \mathrm{C}\right)$

$T_{r t} \quad$ Equilibrium temperature of the cylindrical radiation thermometer

$T_{s f} \quad$ Outer surface temperature of the body $\left({ }^{\circ} \mathrm{C}\right)$

$T_{s k} \quad$ Skin temperature $\left({ }^{\circ} \mathrm{C}\right)$

$V \quad$ Air velocity $\left(\mathrm{m} \mathrm{s}^{-1}\right)$

$v \quad$ Kinematic viscosity of air $\left(\sim 1.5 \times 10^{-5} \mathrm{~m}^{2} \mathrm{~s}^{-1}\right)$

$z \quad$ Height (m)

$\alpha_{h} \quad$ Average skin and clothing albedo of a human

$\rho C_{p} \quad$ Volumetric heat capacity of air $\left(\sim 1200 \mathrm{~J} \mathrm{~m}^{-3} \mathrm{~K}^{-4}\right)$

$\sigma \quad$ Stefan-Boltzman constant $\left(5.67 \times 10^{-8} \mathrm{~W} \mathrm{~m}^{-2} \mathrm{~K}^{-4}\right)$

$\varepsilon \quad$ Emissivity

$\varepsilon_{h} \quad$ Emissivity of a human

Acknowledgement Funding for this project was generously provided by the Natural Sciences and Engineering Research Council of Canada (NSERC).

\section{References}

ACSM (1998) ACSM position stand: The recommended quantity and quality of exercise for developing and maintaining cardiorespiratory and muscular fitness, and flexibility in healthy adults. Med. Sci. Sports Exerc. 3O(6):975-991

ACSM (2006) ACSM's guidelines for exercise testing and prescription. Lippincott Williams and Wilkins, 7th edition

Ahmed K (2003) Comfort in urban spaces: defining boundaries of outdoor thermal comfort for the tropical environments. Energy Build 35:103-110

Ainsworth B, Haskell W, Whitt M, Irwin M, Swartz A, Strath S, O'Brien W, Bassett D Jr, Schmitz K, Emplaincourt P, Jacobs D Jr, Leon A (2000) Compendium of physical activities: an update of activity codes and MET intensities. Med. Sci. Sports Exerc. 32:S498-S516

Batte A, Darling J, Evans J, Lance LM, Olson E, Pincivero D (2003) Physiologic response to a prescribed rating of perceived exertion on an elliptical fitness cross-trainer. J Sports Med Phys Fitness 43:300-305

Borg G (1982) Psychophysical bases of perceived exertion. Med Sci Sports Exerc 14:377-381

Bouskill L, Havenith G, Kuklane K, Parsons K, Withey W (2002) Relationship between clothing ventilation and thermal insulation. AIHA 63:262-268

Brown R, Gillespie T (1986) Estimating outdoor thermal comfort using a cylindrical radiation thermometer and an energy budget model. Int J Biometeorol 3O(1):43-52

Brown, R., Gillespie, T. (1995) Microclimatic landscape design. Wiley, New York

Campbell GS (1977) An introduction to environmental biophysics. Springer, Berlin

Campbell G, Norman J (1998) An introduction to environmental biophysics, 2nd edn. Springer, New York

Dunbar C, Robertson R, Baun R, Blandin M, Metz K, Burdett R, Goss $\mathrm{F}$ (1992) The validity of regulating exercise intensity by ratings of perceived exertion. Med. Sci. Sports Exerc. 24:94-99

Eliasson I, Knez I, Westerberg U, Thorsson S, Lindberg F (2007) Climate and behaviour in a Nordic city. Landsc. Urban Plan. 82:72-84

Erlandson T, Krzysztof C, De Dear R, Havenith G (2003) Environmental and human factors influencing thermal comfort of office occupants in hot - humid and hot-arid climates. Ergonomics 46:616-628

Fanger P (1972) Thermal comfort. McGraw-Hill, New York

Gaitani N, Mihalakakou G, Santamouris M (2007) On the use of bioclimatic architecture principles in order to improve thermal conditions in outdoor spaces. Build. Environ 42:317-324

Gavhed D, Holmer I (1996) Physiological and subjective responses to thermal transients of exercising subjects dressed in coldprotective clothing. Eur J Appl Physiol 73:573-581

Harlan S, Brazel B, Prashad L, Stefanov W, Larsen L (2006) Neighborhood microclimates and vulnerability to heat stress. Soc Sci Med 63:2847-2863

Havenith G, HeusR,Lotens WA (1990) Clothing ventilation, vapourresistance and permeability index: changes due to posture, movement andwind. Ergonomics 33:989-1005

Havenith G, Holmer I, Parsons K (2002) Personal factors in thermal comfort assessment: clothing properties and metabolic heat production. Energy Build 34:581-591

Holmer I, Nilsson H, Havenith G, Parsons K (1999) Clothing convective heat exchange - proposal for improved prediction in standards and models. Ann Occup Hyg 43:329-337

Hoppe P (1999) The physiological equivalent temperature - a universal index for the biometeorological assessment of the thermal environment. Int J Biometeorol 43:71-75 
Hoppe P (2002) Different aspects of assessing indoor and outdoor thermal comfort. Energy Build 34:661-665

Isaac S, Michael W (1997) Handbook in research and evaluation, 3rd edn. EdITS, California

ISO (2007) IS0 9920 Ergonomics of the thermal environment estimation of the thermal insulation and water vapour resistance of a clothing ensemble. International Organization for Standardization, Geneva, Switzerland

Johansson E, Emmanuel R (2006) The influence of urban design on outdoor thermal comfort in the hot, humid city of Columbo, Sri Lanka. Int J Biometeorol 51:119-133

Kang J, Schweitzer J, Hoffman J (2003) Effect of order of exercise intensity upon cardiorespiratory, metabolic, and perceptual responses during exercise of mixed intensity. Eur J Appl Physiol 90:569-574

Kenny N, Warland J, Brown R, Gillespie R (2008) Estimating the radiation absorbed by a human. Int $\mathrm{J}$ Biometeorol 52(6):491-503

Kerslake DM (1972) The stress of hot environments. Cambridge University Press, Cambridge

Knez I, Thorsson S (2006) Influences of culture and environmental attitude on thermal, emotional and perceptual evaluations of a public square. Int. J. Biometeorol 50:258-268

Kreith F, Black WZ (1980) Basic heat transfer. Harper and Row, New York

Lamb K, Eston R, Corns D (1999) Reliability of ratings of perceived exertion during progressive treadmill exercise. Br J Sports Med 33:336-339

Maw G, Boutcher S, Taylor N (1993) Ratings of perceived exertion and affect in hot and cool environments. Eur J Appl Physiol 67:174-179

Mayer H, Hoppe P (1987) Thermal comfort of man in different urban environments. Theor. Appl. Climatol 38:43-49

Nielsen B (1988) Heat balance during exercise in the sun. Eur J Appl Physiol 58:189-196
Nielsen B (1990) Solar heat load: heat balance during exercise in clothed subjects. Eur J Appl Physiol 60:452-456

Nikolopoulou M, Lykoudis S (2006) Thermal comfort in outdoor urban spaces: Analysis across different European countries. Build. Environ 41:1455-1470

Nikolopoulou M, Steemers K (2003) Thermal comfort and psychological adaptation as a guide for designing urban spaces. Energy Build 35:95-101

Nikolopoulou M, Baker N, Steemers K (2001) Thermal comfort in outdoor urban spaces: Understanding the human parameter. Sol Energy 70(3):227-235

Noble B, Borg G, Jacobs I, Ceci R, Kaiser P (1983) A category-ratio perceived exertion scale: relationship to blood and muscle lactates and heart rate. Med. Sci. Sports Exerc. 15:523-528

Parsons K (2003) Human Thermal Environments, 2nd edn. Taylor \& Francis, New York, NY

Parsons K, Havenith G, Holmer I, Nilsson H, Malchaire J (1999) The effects of wind and human movement on the heat and vapour transfer properties of clothing. Ann Occup Hyg 43:347-352

Schiller G (2001) Biometeorology and recreation in east Mediterranean forests. Landsc. Urban Plan. 57:1-12

Spagnolo J, de Dear R (2003a) A field study of thermal comfort in outdoor and semi-outdoor environments in subtropical Sydney Australia. Build. Environ 38:721-738

Spagnolo J, de Dear R (2003b) A human thermal climatology of subtropical Sydney. Int J Climatol 23:1383-1395

Thorsson S, Lindqvist M, Lindqvist S (2004) Thermal bioclimatic conditions and patterns of behaviour in an urban park in Goteborg, Sweden. Int J Biometeorol 48:149-156

Thorsson S, Honjo T, Lindberg F, Eliasson I, Lim E (2007) Thermal comfort and outdoor activity in Japanese urban public places. Environ Behav 39:660-684

Virokannas H (1996) Thermal responses to light, moderate and heavy daily outdoor work in cold weather. Eur J Appl Physiol 72:483-489 